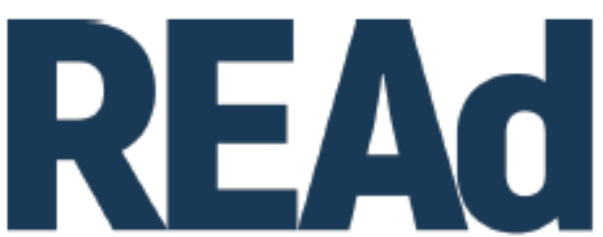

Revista Eletrônica de Administração

\title{
PROGRAMA MAIS MÉDICOS E INDICADORES DA ATENÇÃO PRIMÁRIA À SAÚDE EM MINAS GERAIS (2013-2015) ${ }^{1}$
}

\author{
Débora Gonzaga Martin² \\ Sabrina Olímpio Caldas de Castro ${ }^{3}$ \\ Camila Henriques de Paula ${ }^{4}$ \\ Luiz Antônio Abrantes 5
}

http://dx.doi.org/10.1590/1413-2311.287.96302

\section{RESUMO}

As grandes desigualdades socioeconômicas e a extensão territorial brasileira contribuem para um acesso à saúde pública desproporcional entre os municípios brasileiros. Nesse sentido, políticas públicas foram implantadas para diminuir tais disparidades. Sendo assim, o seguinte trabalho objetiva analisar os efeitos e implicações do provimento de profissionais da saúde no desempenho da Atenção Primária à Saúde (APS) nos municípios mineiros. Para atender ao objetivo do estudo, os municípios mineiros foram divididos entre dois grupos, estratificados conforme a taxa de médicos atuantes no Sistema Único de Saúde (SUS) a fim de se aplicar o Teste $\mathrm{T}$ de diferença entre médias. Os resultados demonstraram que o Programa Mais Médicos (PMM) refletiu no desempenho da APS, ao aumentar o quantitativo de médicos, expandir as equipes da Estratégia Saúde da Família, ampliar a cobertura da APS e o número de procedimentos de Atenção Básica $(A B)$. Ademais, verificou-se que municípios em vulnerabilidade, beneficiados com a política do governo federal, não conseguem ofertar as condições adequadas para cumprir as metas. Portanto, conclui-se que o PMM é importante

\footnotetext{
${ }^{1}$ Recebido em 9/9/2019, aceito em 10/6/2020.

2 Universidade Federal de Viçosa, Viçosa - MG (Brasil); http://orcid.org/0000-0002-8392-6751; debora.martin@ufv.br.

3 Universidade Federal de Viçosa, Viçosa - MG (Brasil); http://orcid.org/0000-0002-9130-782X; sabrinadekastro@hotmail.com.

4 Universidade Federal de Viçosa, Viçosa - MG (Brasil); http://orcid.org/0000-0001-9570-6900; camila.paula@ufv.br.

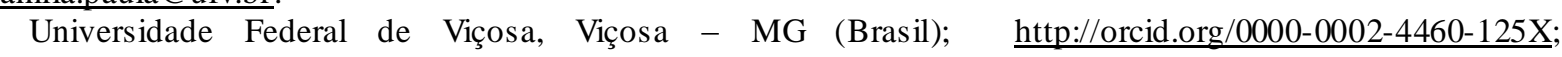
abrantes@ufv.br.
} 
para diminuir as iniquidades de saúde no Brasil, apesar da necessidade de criação de estratégias para os municípios altamente vulneráveis conseguirem implementar e concluir a política.

Palavras-chave: PMM. Atenção Primária. Programa Mais Médicos. SUS.

\title{
THE PROVISION AND IMPLICATIONS OF "PROGRAMA MAIS MÉDICOS” IN THE INDICATORS OF PRIMARY HEALTH CARE IN MINAS GERAIS 2013-2015
}

\begin{abstract}
Due to the great socioeconomic inequalities and the great Brazilian territorial extension, there is a disproportion of access to public health among Brazilian municipalities. Thus, several public policies have been implemented in order to reduce these disparities. Therefore, the following work aims to analyze the effects and implications of the provision of health professionals on the performance of Primary Health Care (PHC), in the municipalities of Minas Gerais. To meet the objective of the study, the Minas Gerais municipalities were divided between two groups. Subsequently, each group was stratified, according to the rate of doctors working in SUS. Finally, the T test of difference between means was applied. In the results it was possible to observe that the PMM brought several advances to the performance of PHC: increase of doctors in PHC; expansion of the Family Health Strategy teams; expansion of PHC coverage and expansion of the number of PHC procedures. In addition, it was found that vulnerable municipalities often receive federal government policy, but do not have the right conditions to return and meet their goals. It concludes the importance of the PMM to reduce health inequities in Brazil, however, strategies must be created so that highly vulnerable municipalities are able to provide the necessary return for the good progress of the policy.
\end{abstract}

Keywords: PMM. Primary Attention. Programa Mais Médicos. SUS.

\section{DISPOSICIÓN E IMPLICACIONES DEL PROGRAMA MÁS MÉDICOS EN LOS INDICADORES DE ATENCIÓN PRIMARIA DE SALUD EN MINAS GERAIS 2013- 2015}

\section{RESUMEN}

Debido a las grandes desigualdades socioeconómicas y a la gran extensión territorial brasileña, existe una desproporción de acceso a la salud pública entre los municipios (c) (1) $\Theta$ REAd | Porto Alegre - Vol. 26 - N. ${ }^{\circ} 2$ - Maio / Agosto 2020 - p. 352-380. 
brasileños. Por lo tanto, se han implementado varias políticas públicas para reducir estas disparidades. Por lo tanto, el siguiente trabajo tiene como objetivo analizar los efectos e implicaciones de la provisión de profesionales de la salud en el desempeño de la Atención Primaria de Salud (APS), en los municipios de Minas Gerais. Para cumplir con el objetivo del estudio, los municipios de Minas Gerais se dividieron en dos grupos. Posteriormente, cada grupo se estratificó, de acuerdo con la tasa de médicos que trabajan en el SUS. Finalmente, se aplicó la prueba T de diferencia entre medias. En los resultados fue posible observar que el PMM trajo varios avances en el desempeño de la APS: aumento de médicos en APS; expansión de los equipos de la Estrategia de salud familiar; expansión de la cobertura de APS y expansión del número de procedimientos AB. Además, se descubrió que los municipios vulnerables a menudo reciben la política del gobierno federal, pero no tienen las condiciones adecuadas para cumplir sus objetivos. Concluye la importancia del PMM para reducir las inequidades en salud en Brasil, sin embargo, se deben crear estrategias para que los municipios altamente vulnerables puedan proporcionar el retorno necesario para el buen progreso de la política.

Palabras clave: PMM. Atención Primaria. Más Médicos. SUS.

\section{INTRODUÇÃO}

No início dos anos 2000, o cenário socioeconômico brasileiro foi marcado por diversos avanços, com destaque para a redução da pobreza, ampliação da economia, geração de empregos e melhoria na saúde pública. Contudo, em função da grande extensão territorial do país, marcada pelas desigualdades regionais, esses avanços não aconteceram de forma homogênea, afetando diretamente o equilíbrio da oferta de bens e serviços públicos em determinadas regiões.

No caso específico da saúde, direito de todos e dever do Estado, nos termos da Constituição Federal de 1988, deve ser garantida mediante políticas sociais e econômicas e com acesso universal e igualitário às ações e serviços para sua promoção, proteção e recuperação. Apesar dessas garantias, ainda são observadas grandes iniquidades em sua oferta e desempenho no país. Martin et al. (2018) avaliou a influência do controle social no desempenho da saúde pública e apontou as distorções do acesso à saúde no Brasil, caracterizado como precário principalmente nas regiões Norte e Nordeste e em municípios de vulnerabilidade social. As principais causas dessas distorções são ocasionadas, na visão de Girardi (2011), pela ausência e pela distribuição geográfica irregular de médicos no país, que 
culminou em problemas persistentes por décadas, cuja resolução demanda a adoção de medidas e a formulação de políticas públicas.

Dentre essas medidas, destaca-se a criação do Sistema Único de Saúde - SUS na Constituição Federal de 1988 e, posteriormente, sua regulação por meio da Lei 8.080/1990, quando coube ao Estado prover as condições indispensáveis ao pleno exercício da saúde mediante a formulação e execução de políticas econômicas e sociais. Nesse contexto, destacam-se, também, o Programa Saúde da Família, depois, denominado, Estratégia Saúde da Família (ESF) e o Programa de Agentes Comunitários de Saúde, todos (PACS) voltados para o atendimento da Atenção Primária à Saúde (APS). Os focos desses programas são a família e a importância do desenvolvimento de uma atenção integral, com interferência direta nas condições e determinantes da saúde em coletividade (BRASIL, 2011; MACHADO et al., 2007).

O crescimento na cobertura da ESF, entre 2008 e 2015, correspondeu a 1,5\%, sendo que a dificuldade em atrair e reter os médicos para as equipes representou um grande obstáculo (BRASIL, 2015). Apesar do avanço dos programas ESF e PACS para o provimento da saúde, o país ainda enfrentava desafios relacionados à ausência de cobertura da atenção básica em diversas regiões. Deste modo, o Estado criou estratégias para reduzir as desigualdades no acesso à saúde pública, principalmente na Atenção Primária.

A Lei 12.871/2013 instituiu o Programa Mais Médicos (PMM), com a finalidade de formar recursos humanos na área médica e diminuir a carência de médicos nas regiões de vulnerabilidade social, prioritárias para o SUS. A intenção desse programa consistia em reduzir as desigualdades regionais na área de saúde, fortalecer o acesso à atenção primária por meio da melhoria de infraestrutura das Unidades Básicas de Saúde (UBS) e ampliar a capacitação profissional dos médicos no Brasil (BRASIL, 2013). Desse modo, o Projeto Mais Médicos para o Brasil (PMMB) definiu, na Portaria 1369/2013, as regiões de prioridade com ênfase em municípios de extrema pobreza, alta vulnerabilidade social e Distritos Sanitários Indígenas (BRASIL, 2013).

Conforme dados do SAGE (2018), dos 4.058 municípios que aderiram ao programa, 34,10\% eram considerados de extrema pobreza. Em 2018, o Programa Mais Médicos possuía mais de 16 mil médicos ativos atuando em quase $70 \%$ dos municípios brasileiros, inclusive em Distritos Sanitários Especiais Indígenas (DSEIs), e atendeu em média $81 \%$ dos municípios em extrema pobreza. O Programa conseguiu acolher cerca de 57 milhões de cidadãos em diferentes regiões do Brasil (SAGE, 2018). Contudo, apesar de a política ter objetivos voltados para áreas prioritárias de vulnerabilidade em saúde, estudos têm apontado que o (c) (1) $\Theta$ REAd | Porto Alegre - Vol. 26 - N. ${ }^{\circ} 2$ - Maio / Agosto 2020 - p. 352-380. 
acesso aos Recursos Humanos de Saúde (RHS) e a estrutura da Atenção Básica permanecem inferiores nas regiões de vulnerabilidade se comparados às demais.

Sendo assim, para verificar a importância dessa Política Pública na redução das desigualdades de acesso à saúde pública entre os municípios brasileiros, questiona-se: quais os efeitos do Programa Mais Médicos no provimento e no desempenho da Atenção Primária à Saúde?

Portanto, o objetivo desse trabalho consiste em analisar os efeitos e as implicações do provimento de profissionais da saúde no desempenho da Atenção Primária à Saúde dos municípios do Estado de Minas Gerais. Parte-se da hipótese de que as políticas relacionadas ao programa interferiram positivamente nos indicadores dos municípios conte mplados.

Especificamente, pretende-se:

a) identificar e caracterizar os municípios mineiros em relação ao provimento de profissionais da saúde ao observar seus indicadores socioeconômicos;

b) avaliar os efeitos do Programa no desempenho da atenção primaria à saúde nos municípios mineiros.

Tal estudo se destaca por sua expectativa em oferecer subsídios para conhecer e avaliar os resultados do Programa, bem como os efeitos da política nos diferentes municípios, viabilizando dessa forma a criação e o aperfeiçoamento das estratégias existentes para amenizar as iniquidades de acesso à APS no país.

O artigo está estruturado primeiramente em uma revisão de literatura acerca do Programa Mais Médicos e a sua importância para a Atenção Primária à Saúde. Posteriormente, apresenta-se a metodologia utilizada para atender aos objetivos, seguida dos resultados obtidos com sua aplicação e, por fim, as referências bibliográficas.

\section{O PROGRAMA MAIS MÉDICOS NA ATENÇÃO PRIMÁRIA À SAÚDE}

A descentralização promovida pelo federalismo aproximou o governo dos cidadãos, com o objetivo de facilitar a fiscalização das ações públicas e a possibilidade de observar as necessidades populacionais mais de perto. Com isso, contribuiria para a criação de políticas mais efetivas. Todavia, a descentralização e a autonomia concedida aos municípios trouxeram dificuldades, pois aumentaram as obrigações em decorrência de novas demandas por saúde, habitação, saneamento e educação, sem um respectivo recebimento ou arrecadação de receitas suficientes para cobrir tais gastos (S ANTOS,2017). Ampliando, dessa forma, as desigualdades entre as regiões brasileiras. 
No âmbito da saúde, os estudos demonstram a maior concentração de Recursos Humanos de Saúde (RHS) nas regiões Sul e Sudeste, em contraposição à precariedade e deficiência de acesso e distribuição do Norte e Nordeste. Em 2009, a região Sudeste com cerca de $40 \%$ da população brasileira, concentrou $60 \%$ dos recursos humanos médicos no país (GIRARDI, 2011; OLIVEIRA et al., 2016).

Já em 2018, os dados da "Demografia Médica 2018”, publicado pelo Conselho Federal de Medicina, comprovaram o crescimento no quantitativo de médicos no país desproporcional à desigualdade de distribuição dos profissionais. No Sudeste, região com a maior densidade de médicos, havia uma taxa de 2,81 médicos por mil habitantes, enquanto no Norte e Nordeste, essa taxa era de 1,16 e 1,41, respectivamente, no ano de 2018. Além disso, as capitais possuíam as maiores razões de médicos no país, como o Distrito Federal com a taxa de 4,35. Observou-se também que dentro dos próprios municípios existiam desigualdades na distribuição, ou seja, a concentração em regiões mais ricas (DEMOGRAFIA MÉDICA NO BRASIL, 2018). Por outro lado, o estado de São Paulo concentrou 21,7\% da população total e $28 \%$ do total de médicos do país, enquanto o Maranhão manteve a menor razão entre as unidades federativas, com 0,87 médicos por mil habitantes, seguido pelo Pará, com razão de 0,97, destacando a má-distribuição (DEMOGRAFIA MÉDICA NO BRASIL, 2018).

No Brasil, a proporção média de médicos era de 1,8 por mil habitantes, a meta do Programa é alcançar 2,7 até 2026, como destaca Neto e Lima (2019). Em janeiro de 2018, a proporção subiu para 2,18 médicos por mil habitantes, ou seja, o Programa contribuiu para o acréscimo de 18.240 profissionais em $81 \%$ dos municípios brasileiros (BRASIL, 2015).

Nesse contexto, trabalhos apontam para condicionantes que afetam a fixação e retenção de RHSs em determinados contextos geográficos que, por consequência, influenciam no desempenho da Atenção Primária. Os principais condicionantes relatados envolvem fatores individuais dos profissionais de saúde, como idade, renda familiar e oportunidade de emprego para o cônjuge; fatores acerca do sistema educacional, como a presença de cursos de medicina, a educação continuada e a residência médica; fatores organizacionais, como salário, condições de trabalho, reconhecimento profissional e plano de carreira e; fatores relativos às características do município, como Produto Interno Bruto, segurança, Índice de Desenvolvimento Humano e níveis de vulnerabilidade social (DUSSALT; FRANCESCHINI, 2006; PÓVOA; ANDRADE, 2006; MACIEL FILHO, 2007; SOUSA; DAL POZ; BOSCHIPINTO, 2013; PIERANTONI, 2013; SCHEFFER; CASSENOTE; BIANCARELLI, 2015; KIRK; KIRK; MARY, 2015; OLIVEIRA et al., 2017).

(c) (1) $\Theta$ REAd | Porto Alegre - Vol. 26 - N. ${ }^{\circ} 2$ - Maio / Agosto 2020 - p. 352-380. 
Desse modo, para amenizar tais desigualdades de acesso, o Governo Federal criou o Programa Mais Médicos por meio da Lei 12.871, em 2013. A formulação da agenda do programa teve grandes repercussões. A sociedade reivindicou por melhorias no acesso à saúde pública com protestos nas ruas e nas redes sociais, em 2013. Com isso, o governo lançou o tema para uma agenda formal de Política Pública que resultou na criação do PMM.

Por outro lado, os representantes da classe médica se opunham ao programa em razão da escassez de médicos, das precárias condições de trabalho e dos "riscos ao atendimento da população pela supos ta má-formação dos médicos integrantes do Programa, considerando não terem se submetido à prova de revalidação de seus diplomas, o REVALIDA" (NETO; LIMA, 2019, p. 67). Todavia, a implementação do programa ocorreu sob um contexto conturbado e divergente (FEDERAÇÃO NACIONALDOS MÉDICOS, 2013).

O PMM foi instaurado em três eixos estratégicos: 1) formação médica para atendimento da saúde pública, a partir de aumento de vagas de graduação, vagas de residência médica e abertura de novos cursos de medicina; 2) melhoria na infraestrutura das UBSs com os novos investimentos e; 3) o provimento emergencial de médicos em áreas vulneráveis, ou seja, que não possuem equipe médica suficiente à população (BRASIL, 2013).

Assim, procurando atingir os objetivos propostos, o eixo de provimento emergencial de médico foi estruturado no Projeto Mais Médicos para o Brasil - PMMB, que definiu na Portaria 1369/2013 quais seriam suas regiões prioritárias:

a) ter o Município $20 \%$ (vinte por cento) ou mais da população vivendo em extrema pobreza; b) estar entre os 100 (cem) Municípios com mais de 80.000 (oitenta mil) habitantes, com os mais baixos níveis de receita pública "per capita" e alta vulnerabilidade social de seus habitantes; c) estar situado em área de atuação de Distrito Sanitário Especial Indígena (DSEI/SESAI/MS), órgão integrante da Estrutura Regimental do Ministério da Saúde; ou d) estar nas áreas referentes aos $40 \%$ (quarenta por cento) dos setores censitários com os maiores percentuais de população em extrema pobreza dos Municípios (BRASIL, 2013).

Estudos anteriores demonstraram uma menor fixação de médicos onde os profissionais possuíam dificuldades geográficas de acesso à Unidade Básica de Saúde, ou percebiam não serem capacitados para o trabalho, ou a infraestrutura e os recursos materiais eram precários (GIOVANELLA et al., 2016). Afinal, as inadequações das unidades de saúde prejudicam o desenvolvimento e a qualidade das ações na $\mathrm{AB}$, pois culmina em insatisfação nos profissionais e usuários. Com isso, limita-se o potencial dos serviços para a consolidação da ESF na busca pela reorganização de práticas centradas na tríade indivíduo-famíliacomunidade e na qualidade da atenção à saúde, como destacado por Moreira et al. (2017). 
O PMM visa regiões com escassez médica, porém, as UBSs com condições de infraestruturas precárias têm menores de aderirem ao programa. A final, a elevada rotatividade nessas regiões vulneráveis reflete em maiores despesas e na qualidade dos serviços prestados, incorrendo em círculo vicioso. Por isso, a concentração de profissionais em UBS com cond ições de infraestrutura favoráveis compromete a meta de reduzir as iniquidades de acesso à APS (CAMPOS; MALIK, 2008; GIOVANELLA et al., 2016).

Diante da dificuldade de reter profissionais brasileiros em áreas de vulnerabilidade, a Portaria interministerial $\mathrm{n}^{\mathrm{o}} 1369$, de 8 de julho de 2013, incluiu profissionais médicos estrangeiros como elegíveis ao Programa . Na Portaria, os perfis dos médicos elegíveis ao PMM eram em ordem de prioridade:

\footnotetext{
I - médicos formados em instituições de educação superior brasileira ou com diplo ma revalidado no País, inclusive os aposentados;

II - médicos brasileiros formados em instituições estrangeiras com habilitação para exercício da Medicina no exterior; e

III - médicos estrangeiros com habilitação para exercício da Medicina no exterior (BRASIL, 2013).
}

Comes et al. (2016) estudaram 32 municípios das cinco regiões brasileiras e constataram, naquele ano, que 78\% dos profissionais do PMM eram de origem cubana , 17\% de nacionalidade brasileira, um boliviano e um espanhol. Portanto, esta estratégia representou uma forma do governo federal aumentar a presença de médicos em regiões vulneráveis (BRASIL, 2013).

Após a consolidação do Programa, os Distritos Sanitários Especiais de Saúde Indígena e as Unidades Básicas de Saúde fluviais ribeirinhas da Amazônia no Semiárido e comunidades rurais, quilombolas, assentamentos, periferia e morros das grandes cidades contaram com equipes de méd icos e o acesso à atenção básica (BRASIL, 2015).

Neto e Lima (2019, p. 67) destacaram que nos "municípios que aderiram ao Programa, o número de médicos saltou de 46.674, em 2011, para 54.525, em 2015; já nos municípios que não aderiram, o crescimento foi de 6.918, em 2011, para 7.385, em 2015.” Afinal, a atenção primária à saúde visa alcançar os atributos essenciais por meio da atenção no primeiro contato, longitudinalidade, integralidade e coordenação (STARFIELD, 2002).

\section{METODOLOGIA}

Para atender ao objetivo do estudo, os municípios mineiros foram inicialmente divididos em dois grupos: municípios que aderiram ao Programa Mais Médicos em 2013 
(Grupo 1) e municípios que não aderiram ao Programa em momento algum (Grupo 2). Logo, destaca-se que foram excluídos da amostra os municípios mineiros que aderiram ao Programa em 2014 e 2015. Assim, a amostra final foi composta por 176 municípios no Grupo 1 e 382 municípios no Grupo 2.

Posteriormente, cada um dos grupos foi estratificado, conforme a variável TxMed_AB, a qual indica a quantidade de médicos (Médico da Estratégia de Saúde da Família, Médico de Família e Comunidade, Médico Pediatra) que atuam diretamente no SUS em relação à população com maior prioridade de cobertura de atenção básica.

Destaca-se que a estratificação se torna necessária para comparar municípios semelhantes que aderiram e não aderiram ao Programa. Assim, cada um dos dois grupos foi estratificado em quatro extratos, sendo eles, Extrato 1: de 0 a 1 médicos; Extrato 2: de 1 a 2 médicos; Extrato 3: de 2 a 3 médicos; Extrato 4: acima de 3 médicos. As análises também foram separadas por categorias (População, Recursos Humanos, Estrutura e Atendimentos).

De posse do agrupamento e estratificação, inicialmente, realizou-se a análise descritiva das variáveis adotadas, as quais se encontram dispostas na Tabela 1. Esta análise possibilitou contemplar o objetivo específico de identificar e caracterizar os municípios mineiros em relação ao provimento de profissionais da saúde ao observar seus indicadores socioeconômicos.

Tabela 1 - Descrição das variáveis

\begin{tabular}{|c|c|c|}
\hline Sigla & Variável & Descrição \\
\hline Pop & População & Pro xy do tamanho da demanda por serviços médicos; \\
\hline TxMed_AB & Médicos da AB & $\begin{array}{l}\text { Indica a quantidade de médicos que atuam diretamente no SUS } \\
\text { em relação à população com maior prioridade de cobertura de } \\
\text { atenção básica; }\end{array}$ \\
\hline TxESF & Equipes de Saúde & $\begin{array}{l}\text { Mede a capacidade de cobertura populacional das equipes de } \\
\text { saúde do município; }\end{array}$ \\
\hline TxEst & Núm. de Estabelecimentos & Quantitativo de estabelecimentos de saúde contidos no CNES; \\
\hline TxAt_Diabt & $\begin{array}{l}\text { Média de atendimentos por } \\
\text { pessoa com diabetes }\end{array}$ & $\begin{array}{l}\text { Nú mero méd io de atendimentos para a população com diabetes } \\
\text { mellitus; }\end{array}$ \\
\hline TxAt_Prenatal & Atend. Pré-Natal & Taxa de atendimentos de pré-natal; \\
\hline Pri_AB & $\begin{array}{l}\text { Prioridade de atenção } \\
\text { básica }\end{array}$ & $\begin{array}{l}\text { Estimativa da população com maior prioridade de cobertura } \\
\text { pela atenção básica; }\end{array}$ \\
\hline TxAt_PrevCit & $\begin{array}{l}\text { Proporção de mu lheres } \\
\text { com exame citopatológico } \\
\text { realizado; }\end{array}$ & $\begin{array}{l}\text { Expressa a produção e a oferta de exames citopatológicos do } \\
\text { colo do útero (Papanicolau) em re lação à população fe min ina } \\
\text { dos } 15 \text { aos } 59 \text { anos; }\end{array}$ \\
\hline At_HipAr & $\begin{array}{l}\text { Taxa de atendimentos de } \\
\text { pessoa com hipertensão }\end{array}$ & $\begin{array}{l}\text { Taxa de atendimentos na população hipertensa, residente em } \\
\text { determinado local e período; }\end{array}$ \\
\hline TxNgest & $N^{\circ}$ Gest. $<20$ anos & $\begin{array}{l}\text { Nú mero de gestantes menores de } 20 \text { anos, cadastradas em } \\
\text { relação ao número de gestantes acompanhadas; }\end{array}$ \\
\hline
\end{tabular}




\begin{tabular}{|c|c|c|}
\hline At_Puer & $\begin{array}{l}\text { Taxa de atendimentos de } \\
\text { puericultura }\end{array}$ & $\begin{array}{l}\text { Nú mero médio de atendimentos de puericultura } \\
\text { (acompanhamento de crescimento e desenvolvimento) por } \\
\text { criança menor de } 2 \text { anos, cadastrada; }\end{array}$ \\
\hline Tax_consul & $\begin{array}{l}\text { Proporção de consultas } \\
\text { médicas }\end{array}$ & $\begin{array}{l}\text { Fornece estimativa da suficiência da oferta total de consultas } \\
\text { médicas diante da demanda potencial da população cadastrada; }\end{array}$ \\
\hline TxEncam_Esp & $\begin{array}{l}\text { Encaminhamento para } \\
\text { atendimento es pecializado }\end{array}$ & $\begin{array}{l}\text { Nú mero de encaminhamentos para atendimento especializado } \\
\text { em relação ao total de consultas médicas básicas; }\end{array}$ \\
\hline TxEncam_Urg & $\begin{array}{l}\text { Encaminhamentos para } \\
\text { urgência e e mergência }\end{array}$ & $\begin{array}{l}\text { Proporção dos encaminhamentos para atendimento em serviços } \\
\text { de urgência e emergência em relação ao total de consultas } \\
\text { méd icas básicas; }\end{array}$ \\
\hline TxEncam_IH & $\begin{array}{l}\text { Encaminhamento para } \\
\text { internação hospitalar }\end{array}$ & $\begin{array}{l}\text { Proporção dos encaminhamentos médicos para internação } \\
\text { hospitalar em re lação ao total de consultas médicas básicas; }\end{array}$ \\
\hline ICSAP & $\begin{array}{l}\text { Internações por Condições } \\
\text { Sensíveis à AP (ICSAP) }\end{array}$ & $\begin{array}{l}\text { Razão entre o número de internações hos pitalares por condições } \\
\text { sensíveis à Atenção Primária à Saúde; }\end{array}$ \\
\hline TxVis_med & Visita Médica & $\begin{array}{l}\text { Percentual de visitas domiciliares realizadas pelos profissionais } \\
\text { méd icos em relação à população com prioridade de } \mathrm{AB} \text {; }\end{array}$ \\
\hline TxPS & $\begin{array}{l}\text { Usuários de Planos de } \\
\text { Saúde }\end{array}$ & $\begin{array}{l}\text { Percentual da população coberta por planos e seguros de } \\
\text { assistência suplementar à saúde; }\end{array}$ \\
\hline TхBPBF & Beneficiários do PBF & $\begin{array}{l}\text { Proporção de famílias contempladas com o Programa Bolsa } \\
\text { Família (PBF) em relação à população; }\end{array}$ \\
\hline Pip_percapita & $\begin{array}{l}\text { Produto Interno Bruto per } \\
\text { capita }\end{array}$ & $\begin{array}{l}\text { Valor médio agregado por indivíduo, em moeda corrente e a } \\
\text { preços de mercado, dos bens e serviços finais produzidos; }\end{array}$ \\
\hline TxNvi vos & NascVivos $<2500 \mathrm{~g}$ & $\begin{array}{l}\text { Frequência de nascidos vivos de baixo peso em relação ao total } \\
\text { de nascidos vivos totais; }\end{array}$ \\
\hline Transf_capta & $\begin{array}{l}\text { Transferência Fundo a } \\
\text { Fundo }\end{array}$ & $\begin{array}{l}\text { Repasse por meio da descentralização de recursos diretamente } \\
\text { de fundos da esfera federal para fundos da esfera estadual, } \\
\text { municipal e do Distrito Federal; }\end{array}$ \\
\hline TDIS & $\begin{array}{l}\text { Taxas de distorção idade- } \\
\text { série }\end{array}$ & $\begin{array}{l}\text { Percentual de alunos, em cada série, com idade superior à idade } \\
\text { recomendada (Ensino Fundamental de } 8 \text { e } 9 \text { anos) }\end{array}$ \\
\hline RCPC & Receita corrente per capita & $\begin{array}{l}\text { Somatório das receitas tributárias refe rentes a contribuições, } \\
\text { patrimoniais, industriais, agropecuárias e de serviços, } \\
\text { deduzidos os valores das transferências constitucionais; }\end{array}$ \\
\hline Txagua & Abastecimento de água & Proporção da população coberta com abastecimento de água; \\
\hline Med_PMM & Médicos do PMM & $\begin{array}{l}\text { Quantidade de médicos por município em atividade no PMM } \\
\text { por ano de entrada } ; \text {; }\end{array}$ \\
\hline
\end{tabular}

Para contemplar o segundo objetivo específico, que consiste em avaliar os efeitos do Programa no desempenho da atenção primaria à saúde nos municípios mineiros, realizou-se o Teste $\mathrm{T}$ de diferença entre médias para amostras independentes. Foram realizados testes, para cada uma das variáveis de interesse, em cada um dos extratos, para os anos de 2013 e 2015. A adoção deste método de investigação se justifica em virtude da impossibilidade de inferir que os grupos apresentam ou não diferenças somente pela análise das médias amostrais (LEVIN, 2010). Desta forma, torna-se necessário a utilização do teste para comprovar se a diferença entre os municípios que aderiram e não aderiram ao Programa é atribuída especificamente ao erro amostral ou ao acaso.

O teste de diferença entre médias para amostras independentes é caracterizado pela análise de duas amostras distintas, as quais não possuem relações entre si. Para a aplicação do teste, inicialmente definiu-se a hipótese a ser testada (CARNEIRO et al., 2010), bem como a 
hipótese nula (BRUNI, 2007; LEVIN, 2010). De acordo com Levin (2010), a hipótese nula $\left(H_{0}\right)$ deste estudo parte da premissa de que a diferença entre as amostras dos municípios que aderiram ao Programa e os demais municípios, em cada um dos extratos, se atribui a erros amostrais. Assim sendo, tem-se a seguinte representação:

$$
\mu_{1}=\mu_{2}
$$

Já a hipótese de pesquisa $\left(H_{1}\right)$, com base no autor supracitado, caracteriza-se pela real diferença entre as médias das variáveis dos municípios que aderiram ao Programa e os demais. Sendo assim:

$$
\mu_{1} \neq \mu_{2}
$$

Logo, os procedimentos metodológicos descritos viabilizaram o alcance dos objetivos propostos. Assim, os resultados obtidos pela análise das características dos municípios, bem como pelos testes estatísticos, encontram-se dispostos no tópico subsequente.

\section{CARACTERIZAÇÃO DOS MUNICÍPIOS MINEIROS NO ANO DE IMPLEMENTAÇÃO DO PMM}

Encontram-se neste tópico as estatísticas descritivas das variáveis. Utilizaram-se dados do ano de 2013 com o objetivo de caracterizar os municípios do Estado de Minas Gerais no seu primeiro ano de implementação, considerando os grupos anteriormente divididos, que aderiram (Grupo 1) e não aderiram (Grupo 2) ao programa. As análises também foram divididas em quatro extratos e em categorias, conforme descrito na metodologia. A comparação entre os dois grupos para o Extrato 1 encontra-se disposta na Tabela 2.

\begin{tabular}{|c|c|c|c|c|c|c|c|c|c|}
\hline \multirow[b]{2}{*}{ Categorias } & \multicolumn{5}{|c|}{ Aderiram - Extrato 1 (Num:32) } & \multicolumn{4}{|c|}{ Não aderiram - Extrato 1 (Num:73) } \\
\hline & Variável & Min. & Max. & Média & $\begin{array}{l}\text { Desvio } \\
\text { Padrão }\end{array}$ & Min. & Max. & Média & $\begin{array}{l}\text { Desvio } \\
\text { Padrão }\end{array}$ \\
\hline População & Pop & 3980,0 & 31715,0 & 11442,5 & 7590,3 & 825,0 & 17782,0 & 6476,2 & 3791,5 \\
\hline \multirow{2}{*}{$\begin{array}{l}\text { Recursos } \\
\text { Humanos }\end{array}$} & TxMed_AB & 0,0 & 1,0 & 0,8 & 0,4 & 0,0 & 1,0 & 0,6 & 0,5 \\
\hline & TxESF & 0,0 & 153,6 & 108,8 & 32,8 & 0,0 & 444,6 & 141,7 & 59,5 \\
\hline Estrutura & TxEst & 0,2 & 1,1 & 0,7 & 0,2 & 0,2 & 3,6 & 0,9 & 0,5 \\
\hline \multirow[t]{8}{*}{ Atendimento } & TxAt_Diabt & 0,6 & 129,1 & 37,4 & 26,8 & 2,7 & 161,6 & 37,3 & 28,8 \\
\hline & TxAt_Prenatal & 0,0 & 289,7 & 117,1 & 56,4 & 0,3 & 830,6 & 102,4 & 101,8 \\
\hline & Pri_AB & 3727,0 & 31151,0 & 10792,7 & 6731,7 & 776,0 & 17556,0 & 6001,0 & 3407,2 \\
\hline & TxAt_PrevCit & 0,0 & 90,8 & 23,0 & 15,9 & 0,2 & 579,0 & 33,5 & 66,0 \\
\hline & TxAt_HipA & 5,5 & 91,2 & 25,9 & 18,3 & 0,7 & 125,5 & 26,4 & 22,4 \\
\hline & TxNgest & 6,0 & 38,8 & 20,3 & 6,4 & 5,0 & 43,8 & 20,4 & 6,5 \\
\hline & TxAt_Puer & 1,1 & 220,5 & 53,0 & 51,3 & 0,0 & 286,7 & 45,9 & 44,7 \\
\hline & Tx_Consul & 0,0 & 398,0 & 129,9 & 73,3 & 41,7 & 6954,9 & 290,1 & 828,2 \\
\hline
\end{tabular}

Tabela 2 - Estatísticas descritivas do Extrato 1 


\begin{tabular}{|c|c|c|c|c|c|c|c|c|c|}
\hline & TxEncam_Esp & 0,6 & 31,7 & 7,0 & 6,1 & 0,0 & 30,4 & 4,7 & 4,7 \\
\hline & TxEncam_IH & 0,0 & 3,8 & 0,8 & 0,9 & 0,0 & 6,6 & 0,6 & 1,0 \\
\hline & TxEncam_Urg & 0,0 & 8,8 & 1,6 & 2,1 & 0,0 & 3,6 & 0,6 & 0,7 \\
\hline & ICSAP & 6,3 & 47,3 & 25,0 & 10,3 & 4,3 & 56,4 & 22,9 & 10,1 \\
\hline & TxVis_med & 14,5 & 1983,5 & 159,3 & 347,8 & 20,6 & 2368,7 & 286,7 & 411 \\
\hline & TxPS & 0,3 & 29,2 & 3,9 & 6,2 & 0,3 & 51,5 & 6,1 & \\
\hline \multirow[t]{7}{*}{ Socioeco. } & Txbpbf & 30,3 & 166,9 & 116,9 & 40,3 & 0,0 & 160,0 & 81,0 & 42 \\
\hline & Pip_percapita & 4634,0 & 17862,3 & 7826,8 & 3519,8 & 4631,9 & 106525,4 & 13035,1 & 14072 \\
\hline & TxNvivos & 0,0 & 255,8 & 88,8 & 62,4 & 0,0 & 300,0 & 90,0 & \\
\hline & Transf_capita & 58,4 & 193,8 & 129,3 & 34,9 & 65,4 & 342,9 & 133,7 & 44 \\
\hline & TDIS & 6,2 & 30,0 & 20,3 & 6,0 & 4,8 & 34,7 & 18,4 & \\
\hline & $\mathrm{RCPC}$ & 0,0 & 3360,1 & 1763,7 & 681,2 & 0,0 & 12177,4 & 2800,7 & 1615 \\
\hline & Txagua & 27,8 & 92,6 & 62,4 & 18,4 & 0,0 & 100,0 & 56,7 & 30 \\
\hline
\end{tabular}

Por meio da Tabela 2, é possível observar que 32 municípios que se enquadraram no Extrato 1, ou seja, aqueles municípios que possuíam de 0 a 1 médico da atenção básica, aderiram ao programa em 2013. A população média desses municípios contabilizou cerca de 10 mil habitantes.

Quanto aos Recursos Humanos, a média da capacidade de cobertura populacional das equipes de saúde do município (TxESF) foi de 108,8, sendo que alguns municípios nem sequer apresentaram algum médico ou equipe. Em relação à categoria Estrutura que abarca o número de estabelecimentos de saúde no município, a média foi de 0,7 , sendo constatado que não havia municípios inexistentes de estabelecimentos, apesar da baixa taxa.

Já para a categoria Atendimento, observa-se que muitos municípios não possuíam alguns tipos de atendimentos como: consultas de pré-natal; produção e oferta de exames citopatológicos do colo do útero (Papanicolau); consultas médicas em geral; encaminhamento para atendimento especializado; encaminhamento para atendimento de urgência e emergência.

Quanto à categoria Socioeconômica, a proporção de famílias contempladas com o Programa Bolsa Família alcançou uma taxa mínima de 30 e máxima de 167; um PIB per capita médio de $\mathrm{R} \$ 7.826,00$; uma taxa de distorção idade-série de 20; a proporção da população coberta com abastecimento de água foi de $62,4 \%$ e a receita corrente per capita média foi de $1.763,70$ reais.

Por outro lado, 73 municípios que também se enquadraram no Extrato 1 não aderiram ao programa em momento algum. A população média desses municípios foi de cerca de 6.500 habitantes, ou seja, bem menor do que aqueles que aderiram nesse mesmo extrato. Comparando os indicadores dos municípios enquadrados no Extrato 1, aqueles que 
aderiram e aqueles não aderiram ao programa, pôde-se observar que obtiveram valores próximos na maioria dos indicadores.

Poucos indicadores tiveram valores relativamente distintos entre os municípios que aderiram e aqueles não aderentes. O indicador Pri_AB obteve 11 mil e 6 mil, respectivamente, ou seja, os municípios que aderiram ao programa em 2013 realmente tinham uma população com maior prioridade de cobertura pela atenção básica, quando comparados aqueles que não aderiram nesse mesmo extrato.

A taxa de consultas médicas em geral, a taxa de visitas médicas domiciliares, a taxa de usuários de plano de saúde, o PIB per capita e a receita corrente per capita também foram menores nos municípios que aderiram, ou seja, sinalizam a precariedade no desempenho da atenção básica e na estrutura socioeconômica. Tal fato corrobora com a literatura ao confirmar que os fatores relativos às características do município, como Produto Interno Bruto, educação e renda afetam diretamente os indicadores da saúde (DUSSALT; FRANCESCHINI, 2006; PÓVOA; ANDRADE, 2006; MACIEL FILHO, 2007; SOUSA; DAL POZ; BOSCHI-PINTO, 2013; PIERANTONI, 2013; SCHEFFER; CASSENOTE; BIANCARELLI, 2015; KIRK; KIRK; MARY, 2015; OLIVEIRA et al., 2017).

Por outro lado, a taxa de encaminhamento para atendimento especializado e a taxa de encaminhamento para atendimento de urgência e emergência foram menores nos municípios que não aderiram do Extrato 1. A não adesão de alguns municípios enquadrados no Extrato 1 se deve à contrapartida exigida dos municípios para a instalação do médico, como moradia, alimentação, água potável e "condições adequadas para o exercício das [suas] atividades conforme exigências e especificações da Política Nacional de Atenção Básica (...), tais como ambientes adequados com segurança e higiene, fornecimento de equipamentos necessários, instalações sanitárias e mínimas condições de conforto para o desempenho das atividades" (BRASIL, 2013).

Posteriormente, realizou-se a análise das estatísticas descritivas para ambos os grupos pertencentes ao Extrato 2 (TABELA 3).

Tabela 3 - Estatísticas descritivas do Extrato 2

\begin{tabular}{llrrrrrrrr}
\hline & & \multicolumn{3}{c}{ Aderiram - Extrato 2 (94) } & \multicolumn{3}{c}{ Não aderiram - Extrato 2 (130) } \\
\hline Categorias & Variável & Min. & Max. & Média & $\begin{array}{c}\text { Desvio } \\
\text { Padrão }\end{array}$ & Min. & Max. & $\begin{array}{c}\text { Média } \\
\text { Des vio } \\
\text { Padrão }\end{array}$ \\
\hline População & Pop & 2746,0 & 315819,0 & 22002,1 & 41533,4 & 1785,0 & 87178,0 & 11996,9 & 13124,9 \\
\hline Recursos & TxMed_AB & 1,0 & 2,0 & 1,5 & 0,5 & 1,0 & 2,0 & 1,5 & 0,5
\end{tabular}

(c) (1) $\Theta$ REAd | Porto Alegre - Vol. 26 - N. ${ }^{\circ} 2$ - Maio / Agosto 2020 - p. 352-380. 


\begin{tabular}{|c|c|c|c|c|c|c|c|c|c|}
\hline Hu manos & TxESF & 26,1 & 222,3 & 124,1 & 35,0 & 17,0 & 397,5 & 131,2 & 42,0 \\
\hline Estrutura & TxEst & 0,0 & 1,8 & 0,7 & 0,3 & 0,0 & 2,2 & 0,8 & 0,4 \\
\hline \multirow[t]{14}{*}{ Atendimento } & TxAt_Diabt & 8,7 & 105,0 & 39,5 & 21,9 & 3,1 & 211,0 & 40,6 & 31,2 \\
\hline & TxAt_Prenatal & 0,0 & 1220,0 & 132,6 & 147,0 & 0,0 & 263,6 & 87,2 & 57,4 \\
\hline & Pri_AB & 2706,0 & 244882,0 & 18908,2 & 31444,2 & 1736,0 & 70975,0 & 10939,5 & 11121,1 \\
\hline & TxAt_PrevCit & 4,2 & 57,2 & 24,0 & 10,2 & 0,0 & 110,0 & 23,4 & 13,9 \\
\hline & TxAt_HipA & 4,4 & 2312,0 & 67,6 & 286,7 & 1,6 & 99,9 & 24,8 & 19,9 \\
\hline & TxNgest & 6,6 & 43,1 & 20,5 & 6,2 & 1,4 & 36,0 & 19,3 & 6,7 \\
\hline & TxAt_Puer & 2,1 & 195,8 & 37,2 & 32,9 & 0,0 & 2245,5 & 55,7 & 196,1 \\
\hline & Tx_Consul & 53,8 & 3546,3 & 218,3 & 495,2 & 0,0 & 4069,2 & 178,8 & 352,8 \\
\hline & TxEncam_Esp & 0,0 & 42,1 & 6,3 & 5,5 & 0,0 & 30,8 & 6,0 & 4,8 \\
\hline & TxEncam_IH & 0,0 & 2,6 & 0,5 & 0,6 & 0,0 & 2,0 & 0,4 & 0,4 \\
\hline & TxEncam_Urg & 0,0 & 5,7 & 0,9 & 1,0 & 0,0 & 6,2 & 0,8 & 1,1 \\
\hline & ICSAP & 7,5 & 60,1 & 23,9 & 11,0 & 5,4 & 52,1 & 23,9 & 10,1 \\
\hline & TxVis_med & 3,8 & 1641,4 & 150,3 & 204,6 & 0,0 & 2273,9 & 178,5 & 240,9 \\
\hline & TxPS & 0,1 & 32,0 & 6,0 & 7,9 & 0,2 & 30,6 & 7,0 & 6,7 \\
\hline \multirow[t]{7}{*}{ Socioeco. } & Txbpbf & 19,2 & 180,3 & 112,7 & 41,3 & 6,6 & 178,2 & 85,0 & 41,5 \\
\hline & Pip_percapita & 4180,5 & 28620,1 & 9570,2 & 5499,0 & 4872,4 & 107700,4 & 12426,5 & 10525,2 \\
\hline & TxNvivos & 0,0 & 694,4 & 83,2 & 80,5 & 0,0 & 457,1 & 103,4 & 86,3 \\
\hline & Transf_capita & 45,8 & 256,3 & 140,5 & 38,8 & 37,8 & 307,0 & 136,6 & 44,5 \\
\hline & TDIS & 7,7 & 40,5 & 19,2 & 6,3 & 4,6 & 37,7 & 17,4 & 6,2 \\
\hline & $\mathrm{RCPC}$ & 0,0 & 3920,3 & 1900,3 & 613,0 & 0,0 & 5395,7 & 2362,7 & 948,6 \\
\hline & Txagua & 0,0 & 100,0 & 65,5 & 23,9 & 0,0 & 100,0 & 60,7 & 27,2 \\
\hline
\end{tabular}

Pela Tabela 3, é possível constatar que 94 municípios enquadrados no Extrato 2 possuíam de 1 a 2 médicos da atenção básica e ade riram ao programa, em 2013. A população média de tais alcançou cerca de 22 mil habitantes.

Quanto à categoria Recursos Humanos, a média da capacidade de cobertura populacional das equipes de saúde do município (TxESF) foi de 124,1. Diferente do Extrato 1, todos os municípios do Extrato 2 apresentaram algum médico ou equipe saúde da família e na categoria Estrutura, alguns municípios não possuíam estabelecimentos de saúde.

Já para o Atendimento, observa-se que muitos municípios ainda não apresentaram: consultas de pré-natal; encaminhamento para atendimento especializado; encaminhamento para internação hospitalar; encaminhamento para atendimento de urgência e emergência.

Observando a categoria Socioeconômica, a proporção de famílias contempladas com o Programa Bolsa Família alcançou uma taxa mínima de 19 e máxima de 180 (bem próximas ao do Extrato 1); um PIB per capita médio de $\mathrm{R} \$ 9.570,00$ (pouco acima do Extrato 1); uma taxa de distorção idade-série de 19 (similar ao Extrato 1); a proporção da população coberta com abastecimento de água foi de 65,5\% (similar ao Extrato 1); e a receita corrente per capita média foi de $\mathrm{R} \$ 1.900,00$.

(c) $\left(\right.$ (1) $\Theta$ REAd | Porto Alegre - Vol. 26 - N. ${ }^{\circ} 2$ - Maio / Agosto 2020 - p. 352-380. 
Em contrapartida, 130 municípios, que também se enquadraram no Extrato 2, não aderiram ao programa em momento algum. A população média desses municípios chegou a 12 mil habitantes, ou seja, quase a metade dos que aderiram nesse mesmo extrato e o dobro se comparado ao Extrato 1.

Ao comparar os indicadores dos municípios enquadrados no Extrato 2, que aderiram ou não ao programa, observou-se o alcance de valores próximos na maioria dos indicadores. Apesar das divergências nos indicadores relacionados à taxa de atendimentos a hipertensos, à taxa de consultas médicas em geral e à proporção de famílias contempladas com o Programa Bolsa Família, que foram menores nos municípios não aderentes ao programa. Portanto, evidencia-se uma real necessidade de adesão ao programa de parte dos municípios que não o fizeram em momento algum.

$\mathrm{Na}$ Tabela 4, pode-se observar que 26 municípios enquadraram no Extrato 3 e possuíam de 2 a 3 médicos da atenção básica aderiram ao programa, em 2013. A população média desses contabilizou aproximadamente 32 mil habitantes (10 mil a mais que no Extrato 2).

Tabela 4 - Estatísticas descritivas do Extrato 3

\begin{tabular}{|c|c|c|c|c|c|c|c|c|c|}
\hline \multirow[b]{2}{*}{ Categorias } & \multicolumn{5}{|c|}{ Aderiram - Extrato 3 (26) } & \multicolumn{4}{|c|}{ Não Aderiram - Extrato 3 (95) } \\
\hline & Variável & Min. & Max. & Média & $\begin{array}{l}\text { Desvio } \\
\text { Padrão }\end{array}$ & Min. & Max. & Média & $\begin{array}{l}\text { Desvio } \\
\text { Padrão }\end{array}$ \\
\hline População & Pop & 2567 & 227571 & 31730,6 & 48363,0 & 1227 & 169908 & 16847,1 & 24488,2 \\
\hline \multirow{2}{*}{$\begin{array}{l}\text { Recursos } \\
\text { Hu manos }\end{array}$} & TxMed_AB & 2,0 & 3,0 & 2,5 & 0,5 & 2,0 & 3,0 & 2,4 & 0,5 \\
\hline & TxESF & 66,2 & 184,1 & 126,9 & 32,9 & 51,8 & 289,9 & 129,5 & 38,0 \\
\hline Estrutura & TxEst & 0,0 & 1,6 & 0,6 & 0,3 & 0,1 & 4,1 & 0,9 & 0,5 \\
\hline \multirow[t]{14}{*}{ Atendimento } & TxAt_Diabt & 9,4 & 95,0 & 32,5 & 20,8 & 0,0 & 266,7 & 43,3 & 42,2 \\
\hline & TxAt_Prenatal & 0,0 & 183,3 & 88,4 & 48,3 & 0,0 & 602,8 & 87,3 & 76,7 \\
\hline & Pri_AB & 2476,0 & 144486,0 & 24892,1 & 32704,5 & 1190,0 & 121012,0 & 13733,2 & 18228,0 \\
\hline & TxAt_PrevCit & 6,3 & 58,8 & 24,2 & 12,0 & 0,0 & 50,3 & 20,6 & 10,9 \\
\hline & TxAt_HipA & 7,2 & 62,6 & 23,7 & 14,5 & 0,0 & 172,4 & 28,8 & 28,1 \\
\hline & TxNgest & 9,5 & 33,4 & 21,5 & 5,0 & 0,0 & 46,4 & 20,2 & 6,9 \\
\hline & TxAt_Puer & 3,9 & 90,0 & 32,1 & 18,8 & 0,0 & 306,3 & 42,6 & 47,5 \\
\hline & Tx_Consul & 62,0 & 517,8 & 147,9 & 97,8 & 0,0 & 7960,2 & 305,8 & 912,5 \\
\hline & TxEncam_Esp & 0,1 & 79,2 & 9,3 & 14,9 & 0,0 & 39,5 & 6,1 & 5,6 \\
\hline & TxEncam_IH & 0,0 & 7,0 & 0,6 & 1,4 & 0,0 & 3,0 & 0,4 & 0,5 \\
\hline & TxEncam_Urg & 0,0 & 14,4 & 1,2 & 2,9 & 0,0 & 13,0 & 0,9 & 1,9 \\
\hline & ICSAP & 9,7 & 37,9 & 21,0 & 7,4 & 8,1 & 51,0 & 24,3 & 10,4 \\
\hline & TxVis_med & 12,4 & 363,9 & 116,0 & 92,5 & 0,0 & 19145,7 & 451,6 & 1970,4 \\
\hline & TxPS & 0,4 & 36,5 & 10,9 & 10,4 & 0,2 & 34,3 & 12,0 & 9,7 \\
\hline \multirow[t]{3}{*}{ Socioeco. } & Txbpbf & 14,5 & 173,1 & 85,2 & 46,3 & 19,7 & 153,9 & 65,0 & 34,6 \\
\hline & Pip_percapita & 5859,5 & 45738,0 & 13936,5 & 11227,7 & 5393,9 & 159282,1 & 16733,7 & 19183,3 \\
\hline & TxNvivos & 15,2 & 259,3 & 78,2 & 59,0 & 0,0 & 400,0 & 96,4 & 78,2 \\
\hline
\end{tabular}

REAd | Porto Alegre - Vol. 26 - N. ${ }^{\circ} 2$ - Maio / Agosto 2020 - p. 352-380. 


\begin{tabular}{lrrrrrrrr} 
Transf_capita & 75,2 & 300,2 & 140,3 & 63,4 & 55,9 & 339,8 & 127,4 & 44,8 \\
TDIS & 8,7 & 34,3 & 18,7 & 6,8 & 2,5 & 48,0 & 17,2 & 7,3 \\
RCPC & 0,0 & 5207,4 & 2063,7 & 917,4 & 1474,2 & 7834,8 & 2595,8 & 1283,3 \\
Txagua & 25,0 & 100,0 & 71,6 & 23,2 & 0,0 & 100,0 & 68,8 & 27,0 \\
\hline
\end{tabular}

Na categoria Recursos Humanos, constatou-se que, em média, a capacidade de cobertura populacional das equipes de saúde do município (TxESF) foi de 127. Assim como no Extrato 2, todos os municípios do Extrato 3 apresentaram algum médico ou equipe de saúde da família. Já na categoria Estrutura, identificou-se a presença de municípios sem estabelecimentos de saúde.

Vale ressaltar que nas regiões de difícil acesso aos serviços de saúde, tornou-se necessário a inserção de médicos para atuarem juntos aos demais profissionais das equipes ESF. Afinal, segundo Oliveira et al. (2016, p. 2725), "sem a presença do médico, o atendimento à população fica prejudicado e as ações de atenção integral da saúde limitadas, em decorrência do desfalque da equipe".

Quanto à categoria Atendimento, alguns municípios do Extrato 3, assim como no Extrato 2, ainda não possuíam alguns tipos de atendimentos como: consultas de pré-natal; encaminhamento para internação hospitalar; encaminhamento para atendimento de urgência e emergência.

Já para a categoria Socioeconômica, a proporção de famílias contempladas com o Programa Bolsa Família alcançou uma taxa média de 85 no Extrato 3 (menor do que no Extrato 2); um PIB per capita médio de $\mathrm{R} \$ 14.000,00$ (acima do Extrato 2); uma taxa de distorção idade-série de 18,7 (similar ao Extrato 2); a proporção da população coberta com abastecimento de água foi de 71,6\% (acima do Extrato 2); e a receita corrente per capita média foi de $\mathrm{R} \$ 2.063,00$ (acima do Extrato 2).

Destarte, constata-se que quanto maior o Extrato, menor é a dependência da população em relação ao Programa Bolsa Família, bem como, melhor é o PIB, o nível de educação, de abastecimento de água e de receita corrente, os quais refletem os fatores socioeconômicos.

Por outro lado, 95 municípios também enquadrados no Extrato 3 não aderiram ao programa. A população média desses foi de 17 mil habitantes, ou seja, quase a metade de habitantes dos que aderiram nesse mesmo extrato e cerca de 6 mil a mais se comparado ao Extrato 2.

A comparação entre os indicadores dos municípios enquadrados no Extrato 3, que aderiram ou não ao programa, permite constatar o alcance de valores próximos na maioria dos 
indicadores. Embora os valores relativos aos indicadores da taxa de consultas médicas em geral, da taxa de visita médica e da taxa de nascidos vivos tenham sido diferentes. Enquanto isso, nos extratos anteriores, tais indicadores foram maiores nos municípios que não aderiram ao programa, possivelmente pelo fato de se observar o início de um melhor desempenho nos indicadores de saúde.

Na Tabela 5, retratou-se o maior extrato que englobou acima de 3 médicos da atenção básica, no qual se observou que apenas 24 municípios aderiram ao programa em 2013. Tal fato se deve a esses municípios já possuírem uma quantidade adequada de recursos humanos para sua população, ou seja, não necessitam do programa. A população média dos municípios desse extrato foi de 123 mil habitantes (4 vezes maior que no Extrato 3).

Tabela 5 - Estatísticas descritivas do Extrato 4

\begin{tabular}{|c|c|c|c|c|c|c|c|c|c|}
\hline & \multicolumn{5}{|c|}{ Aderiram - Extrato 4 (24) } & \multicolumn{4}{|c|}{ Não Aderiram - Extrato 4 (84) } \\
\hline Categorias & Variável & Min. & Max. & Média & $\begin{array}{l}\text { Desvio } \\
\text { Padrão }\end{array}$ & Min. & Max. & Média & $\begin{array}{l}\text { Desvio } \\
\text { Padrão }\end{array}$ \\
\hline População & Pop & 4108 & 637961 & 122996,2 & 170105,5 & 1414 & 120223 & 17468,7 & 27750,5 \\
\hline \multirow{2}{*}{$\begin{array}{l}\text { Recursos } \\
\text { Humanos }\end{array}$} & TxMed_AB & 3,0 & 8,0 & 4,8 & 1,5 & 3,0 & 9,0 & 4,5 & 1,3 \\
\hline & TxESF & 65,9 & 230,6 & 121,1 & 47,3 & 0,0 & 323,0 & 137,2 & 53,9 \\
\hline Estrutura & TxEst & 0,2 & 1,7 & 0,5 & 0,3 & 0,3 & 3,3 & 1,0 & 0,7 \\
\hline \multirow[t]{14}{*}{ Atendimento } & TxAt_Diabt & 18,2 & 89,5 & 35,6 & 15,8 & 0,0 & 1226,4 & 49,2 & 131,5 \\
\hline & TxAt_Prenatal & 24,0 & 156,7 & 93,9 & 33,1 & 0,0 & 219,7 & 80,0 & 59,9 \\
\hline & Pri_AB & 3829,0 & 328960,0 & 75416,2 & 94561,6 & 1265,0 & 88974,0 & 12530,6 & 18212,8 \\
\hline & TxAt_PrevCit & 4,6 & 1726,7 & 98,8 & 350,8 & 0,0 & 88,2 & 21,9 & 13,9 \\
\hline & TxAt_HipA & 10,0 & 54,1 & 24,9 & 11,0 & 0,0 & 129,9 & 23,9 & 18,9 \\
\hline & TxNgest & 10,1 & 21,0 & 18,0 & 2,5 & 0,0 & 40,5 & 19,0 & 7,4 \\
\hline & TxAt_Puer & 5,4 & 54,7 & 30,3 & 14,1 & 0,0 & 222,3 & 41,2 & 45,7 \\
\hline & Tx_Consul & 17,3 & 7643,9 & 545,1 & 1611,9 & 0,0 & 388,0 & 136,5 & 59,7 \\
\hline & TxEncam_Esp & 2,7 & 17,1 & 7,6 & 3,7 & 0,0 & 20,2 & 7,7 & 5,3 \\
\hline & TxEncam_IH & 0,0 & 0,8 & 0,2 & 0,2 & 0,0 & 1,9 & 0,3 & 0,5 \\
\hline & TxEncam_Urg & 0,1 & 5,2 & 0,9 & 1,1 & 0,0 & 9,6 & 0,8 & 1,5 \\
\hline & ICSAP & 8,6 & 26,2 & 17,6 & 5,3 & 6,3 & 51,0 & 21,1 & 8,8 \\
\hline & TxVis_med & 15,8 & 704,6 & 151,1 & 159,3 & 0,0 & 1730,2 & 265,3 & 335,6 \\
\hline & TxPS & 6,0 & 49,7 & 29,3 & 13,8 & 1,0 & 67,1 & 17,0 & 15,3 \\
\hline \multirow[t]{7}{*}{ Socioeco. } & Txbpbf & 12,9 & 82,5 & 40,4 & 18,3 & 14,2 & 138,6 & 52,3 & 26,0 \\
\hline & Pip_percapita & 9577,2 & 80729,4 & 26039,6 & 16255,2 & 7975,3 & 340144,7 & 26330,2 & 42194,6 \\
\hline & TxNvivos & 23,3 & 800,0 & 93,0 & 155,7 & 0,0 & 521,7 & 83,4 & 79,3 \\
\hline & Transf_capita & 60,2 & 549,2 & 190,2 & 125,6 & 30,2 & 392,0 & 126,7 & 55,2 \\
\hline & TDIS & 9,2 & 25,6 & 15,8 & 4,9 & 6,4 & 39,1 & 18,2 & 6,6 \\
\hline & $\mathrm{RCPC}$ & 0,0 & 5552,9 & 2131,2 & 1124,9 & 1417,2 & 23382,3 & 3383,3 & 2650,9 \\
\hline & Txagua & 38,1 & 99,9 & 86,0 & 18,6 & 0,0 & 100,0 & 69,6 & 29,5 \\
\hline
\end{tabular}


Por meio da categoria Recursos Humanos, constatou-se que a média da capacidade de cobertura populacional das equipes de saúde do município (TxESF) foi de 121, próximo ao Extrato 3. Todavia, quando se observa a média de médicos da atenção básica, a taxa é mais que o dobro. Diferente dos extratos anteriores, na categoria Estrutura, todos os municípios possuíam estabelecimentos de saúde e na categoria Atendimento, somente a taxa de encaminhamento para internação hospitalar apresentou municípios com valor zero.

O programa contribuiu para a permanência do profissional no município e seu trabalho de acordo com o protocolo da atenção básica. Inclusive para a realização de visitas domiciliares, redução de problemas da atenção primária (AP), potencialização da coordenação dos cuidados mediante a ampliação da oferta e redução das barreiras de acesso, estruturação dos serviços de AP à saúde como porta de entrada do sistema, ampliação da resolutividade e acolhimento (ALMEDA, FAUSTO, GIOVANELLA, 2011).

Já para a categoria Socioeconômica, a proporção de famílias contempladas com o Programa Bolsa Família alcançou uma taxa média de 40 no Extrato 4 (metade do valor do Extrato 3); um PIB per capita médio de $\mathrm{R} \$ 26.000,00$ (quase o dobro do Extrato 3); uma taxa de distorção idade-série de 15,8 (pouco menor que Extrato 3); a proporção da população coberta com abastecimento de água foi de 86\% (bem acima do Extrato 3); e a receita corrente per capita média foi de $\mathrm{R} \$ 2.131,00$ (próximo ao Extrato 3). Nesse caso, observa-se uma melhora significativa dos municípios aderentes ao programa vinculados ao Extrato 4 se comparado aos demais.

Por outro lado, 84 municípios enquadrados no Extrato 4 não aderiram ao programa. A população média desses foi de aproximadamente 17 mil habitantes, ou seja, muito menor do que a dos que aderiram no mesmo extrato. Estes possuem uma população média próxima aos não aderentes do Extrato 3.

Comparando os indicadores dos municípios enquadrados no Extrato 4, que aderiram ou não ao programa, observou-se que a taxa de prioridade da atenção básica nos municípios aderentes foi significativamente superior à dos não aderentes. Portanto, acredita-se que os municípios aderentes no Extrato 4, apesar de possuírem uma taxa de médicos da atenção básica maior, ainda precisavam da adesão ao programa para suprirem e complementarem suas necessidades.

Os resultados do estudo permitem observar as diferentes realidades existentes entre os municípios do Estado de Minas Gerais. Além disso, os indicadores de Atendimento e Estrutura inexistem em alguns municípios, enquanto, em outros, sua representatividade se dá a uma taxa relativamente alta. Constatou-se ainda que a maioria dos Estados mineiros se (c) (i) (\$) REAd | Porto Alegre - Vol. 26 - N. ${ }^{\circ} 2$ - Maio / Agosto 2020 - p. 352-380. 
alocaram no Extrato 2, cuja concentração foi de 1 a 2 médicos da atenção básica, considerados como uma taxa baixa de recursos humanos para atendimento da população.

Ademais, corroborando com Mendonça, Diercks e Kopitkke (2016), quanto maior a população nos extratos maiores os indicadores de saúde do município. Além disso, com base no extrato dos municípios que aderiram ao programa cuja população aumentou, a taxa de prioridade da atenção básica também se elevou. Ou seja, isso possivelmente justifica a adesão dos municípios que possuem maior número de médicos, mas que ainda são insuficientes para cobrir a população atendida.

Após a caracterização da situação dos municípios de ambos os grupos no primeiro ano de aderência ao Programa Mais Médicos, procedeu-se a avaliação dos efeitos e implicações do PMM, disposta no subtópico seguinte.

\section{EFEITOS E IMPLICAÇÕES DO PROGRAMA MAIS MÉDICOS NO DESEMPENHO DA ATENÇÃO PRIMÁRIÀ̀ SAÚDE}

As variáveis relacionadas aos efeitos e implicações do Programa Mais Médicos no desempenho da atenção primária à saúde foram comparadas entre os municípios que aderiram ou não. Inicialmente, procedeu-se à comparação das médias entre os grupos que aderiram e não aderiram, dentro de cada extrato, para o ano de 2013 (TABELA 6). Esta análise permite verificar para quais categorias há diferenças estatisticamente significativas entre a comparação da situação inicial dos municípios que aderiram ao Programa, com seus respectivos similares que não aderiram, considerando o critério de estratific ação.

Tabela 6 - Diferença entre médias para o ano de 2013

\begin{tabular}{|c|c|c|c|c|c|c|c|c|c|}
\hline \multirow[b]{2}{*}{ Categorias } & \multirow[b]{2}{*}{ Variável } & \multicolumn{2}{|c|}{ Extrato 1} & \multicolumn{2}{|c|}{ Extrato 2} & \multicolumn{2}{|c|}{ Extrato 3} & \multicolumn{2}{|c|}{ Extrato 4} \\
\hline & & Dif. & Sig. & Dif. & Sig. & Dif. & Sig. & Dif. & Sig. \\
\hline \multirow{2}{*}{$\begin{array}{l}\text { Recursos } \\
\text { Humanos }\end{array}$} & TxMed_AB & 0,13 & 0,002 & 0,00 & 0,789 & 0,11 & 0,552 & 0,33 & 0,338 \\
\hline & TxESF & $-32,89$ & 0,072 & $-7,17$ & 0,410 & $-2,54$ & 0,964 & $-16,14$ & 0,989 \\
\hline Estrutura & TxEst & $-0,24$ & 0,001 & $-0,13$ & 0,092 & $-0,20$ & 0,117 & $-0,52$ & 0,007 \\
\hline \multirow[t]{6}{*}{ Atendimentos } & TxAt_Diabt & 0,04 & 0,787 & $-1,09$ & 0,079 & $-10,74$ & 0,094 & $-13,62$ & 0,355 \\
\hline & TxAt_Prenatal & 14,69 & 0,341 & 45,40 & 0,314 & 1,06 & 0,399 & 13,87 & 0,000 \\
\hline & Pri_AB & 4791,72 & 0,000 & 7968,71 & 0,001 & 11158,95 & 0,002 & 62885,57 & 0,000 \\
\hline & TxAt_PrevCit & $-10,56$ & 0,404 & 0,53 & 0,141 & 3,62 & 0,960 & 76,84 & 0,000 \\
\hline & TxAt_HipA & $-0,51$ & 0,319 & 42,74 & 0,004 & $-5,14$ & 0,095 & 1,00 & 0,306 \\
\hline & TxNgest & $-0,12$ & 0,777 & 1,22 & 0,106 & 1,24 & 0,230 & $-0,97$ & 0,001 \\
\hline
\end{tabular}




\begin{tabular}{|c|c|c|c|c|c|c|c|c|c|}
\hline & TxAt_Puer & 7,17 & 0,282 & $-18,51$ & 0,192 & $-10,46$ & 0,042 & $-10,84$ & 0,006 \\
\hline & Tx_Consul & $-160,23$ & 0,160 & 39,51 & 0,197 & $-157,91$ & 0,142 & 408,61 & 0,000 \\
\hline & TxEncam_Esp & 2,21 & 0,298 & 0,27 & 0,672 & 3,22 & 0,046 & $-0,17$ & 0,040 \\
\hline & TxEncam_IH & 0,24 & 0,836 & 0,11 & 0,013 & 0,22 & 0,038 & $-0,11$ & 0,003 \\
\hline & TxEncam_Urg & 1,00 & 0,000 & 0,05 & 0,708 & 0,23 & 0,471 & 0,12 & 0,668 \\
\hline & ICSAP & 2,09 & 0,705 & 0,03 & 0,714 & $-3,26$ & 0,042 & $-3,51$ & 0,063 \\
\hline & TxVis_med & $-127,41$ & 0,166 & $-28,13$ & 0,325 & $-335,59$ & 0,231 & $-114,20$ & 0,106 \\
\hline & TxPS & $-2,24$ & 0,655 & $-0,94$ & 0,345 & $-1,13$ & 0,722 & 12,32 & 0,848 \\
\hline \multirow{7}{*}{ Socioeconômicas } & Txbpbf & 35,93 & 0,623 & 27,77 & 0,323 & 20,15 & 0,020 & $-11,88$ & 0,106 \\
\hline & Pip_percapita & $-5208,27$ & 0,045 & $-2856,28$ & 0,139 & $-2797,23$ & 0,682 & $-290,57$ & 0,274 \\
\hline & TxNvivos & $-1,16$ & 0,269 & $-20,19$ & 0,065 & $-18,14$ & 0,201 & 9,57 & 0,216 \\
\hline & Transf_capita & $-4,40$ & 0,441 & 3,81 & 0,044 & 12,90 & 0,022 & 63,48 & 0,000 \\
\hline & TDIS & 1,83 & 0,889 & 1,75 & 0,853 & 1,46 & 0,898 & $-2,38$ & 0,376 \\
\hline & $\mathrm{RCPC}$ & $-1037,03$ & 0,025 & $-462,37$ & 0,000 & $-532,09$ & 0,103 & $-1252,11$ & 0,146 \\
\hline & Txagua & 5,70 & 0,005 & 4,74 & 0,518 & 2,76 & 0,887 & 16,37 & 0,096 \\
\hline
\end{tabular}

Obs: "Dif." consiste na diferença entre as médias dos municíp ios que aderiram ao Programa, reduzida da méd ia dos municípios que não aderiram. Logo, se a diferença for negativa, evidencia que a média nos municípios que não aderiram é superior. Já a coluna "Sig." consiste na significância do teste para cada variável.

A análise realizada permite aferir que, no ano de 2013, havia algumas disparidades significativas entre os municípios que aderiram e não ade riram ao Programa, mesmo considerando o critério de estratificação. Desta forma, evidencia-se que há desigualdades internas nos próprios municípios no que tange ao desempenho da atenção primária à saúde (DEMOGRAFIA MÉDICA NO BRASIL, 2018).

Com relação aos Recursos Humanos, as diferenças se concentram no Extrato 1. Notase que, em média, a quantidade de médicos que atuam diretamente no SUS em relação à população com maior prioridade de cobertura de atenção básica, mensurada pela TxMed_AB, era superior nos municípios que aderiram ao Programa. Em contrapartida, neste mesmo extrato, a capacidade de cobertura populacional das equipes de saúde dos municípios que não aderiram ao programa era, em média, superior à dos municípios que aderiram.

Na categoria Estrutura, comprovou-se que a variável TxEst foi significativa em três dos quatro extratos considerados. Assim, identificou-se que o quantitativo de estabelecimentos de saúde nos municípios que não aderiram ao Programa era, em média, superior ao dos municípios que aderiram ao Programa nos Extratos 1, 2 e 4. Contudo, a adesão ao Programa por municípios com menor quantidade de estabelecimentos pode implicar em desafios para um bom desempenho da política, uma vez que este critério pode indicar aspectos estruturais que afetam a fixação e retenção de RHSs (DUSSALT; 
FRANCESCHINI, 2006; PÓVOA; ANDRADE, 2006; MACIEL FILHO, 2007; SOUSA; DAL POZ; BOSCHI-PINTO, 2013; PIERANTONI, 2013; SCHEFFER; CASSENOTE; BIANCARELLI, 2015; KIRK; KIRK; MARY, 2015; OLIVEIRA et al., 2017). Em contrapartida, evidencia a adesão ao programa de municípios que, de fato, necessitam de melhores cond ições de atendimento à saúde.

No que tange às variáveis de Atendimento, apenas duas apresentaram diferenças significativas entre as médias dos dois grupos no Extrato 1, demonstrando poucas diferenças entre os municípios que aderiram ou não ao Programa. Tal similaridade pode ser justificada por se tratar do Extrato que engloba os municípios mais carentes e precários, resultando em maior homogeneidade entre eles. Especificamente, os municípios que aderiram apresentaram, em média, melhores condições quanto à população com maior prioridade de cobertura pela atenção básica (Pri_AB) e proporção de encaminhamentos para atendimento de urgência e emergência (TxEncam_Urg).

Ainda no que tange ao Atendimento, no Extrato 2, quatro das quatorze variáveis apresentaram diferenças significativas entre as médias dos dois grupos de municípios. Dentre estas, a população com maior prioridade de cobertura pe la atenção básica (Pri_AB), a taxa de atendimentos por pessoa com hipertensão (TxAt_HipA) e a proporção de encaminhamento para internação hospitalar (TxEncam_IH) foram superiores nos municípios que aderiram ao Programa. Já o atendimento a pessoas com diabetes (TxAt_Diabt) foi superior nos municípios que não aderiram ao Programa Mais Médicos.

Em suma, é possível identificar que no Extrato 1 e no Extrato 2, apesar de poucas diferenças significativas entre os municípios que aderiram ou não ao PMM, na categoria Atendimento, as condições dos municípios que aderiram apresentaram resultados estatisticamente superiores no ano de implementação do Programa. Logo, a adesão destes municípios ao PMM indica o compromisso com o atendimento de seus cidadãos.

Em contrapartida, nos demais extratos, houve maior heterogeneidade nas variáveis de Atendime nto, em razão de possuírem diferenças significativas entre suas médias. No Extrato 3, metade das variáveis apresentaram diferenças significativas, ou seja, valores menores que 0,1. Destas, quatro apresentaram uma média superior nos que não ade riram ao Programa, quando comparados aos que aderiram.

Semelhante, no Extrato 4, dez das quatorze variáveis apresentaram diferenças significativas, com médias superiores nos municípios que não aderiram em cinco dessas variáveis. Assim, é possível identificar que os municípios destes extratos que, em 2013, 
aderiram ao PMM apresentavam condições inferiores de atendimento, ou seja, justificava-se a adesão ao Programa.

Por fim, no que tange às Condições Socioeconômicas, esta categoria não apresentou padrão de comportamento, sendo superior às vezes para os municípios que aderiram e, em outros casos, aos que não ade riram. Contudo, é mais frequente a média ser superior aos municípios que não aderiram, indicando que os municípios que ade riram ao PMM, de fato, possuem condições socioeconômicas inferiores a seus pares.

Posteriormente, realizou-se a análise considerando os mesmos extratos para os dados referentes a 2015, com o intuito de aferir se a adoção do Programa levou a modificações no comportamento das variáveis consideradas (TABELA 7).

Tabela 7 - Dife rença entre médias para o ano de 2015

\begin{tabular}{|c|c|c|c|c|c|c|c|c|c|}
\hline \multirow[b]{2}{*}{ Categorias } & \multirow[b]{2}{*}{ Variável } & \multicolumn{2}{|c|}{ Extrato 1} & \multicolumn{2}{|c|}{ Extrato 2} & \multicolumn{2}{|c|}{ Extrato 3} & \multicolumn{2}{|c|}{ Extrato 4} \\
\hline & & Dif. & Sig. & Dif. & Sig. & Dif. & Sig. & Dif. & Sig. \\
\hline \multirow{2}{*}{$\begin{array}{l}\text { Recursos } \\
\text { Hu manos }\end{array}$} & TxMed_AB & 0,38 & 0,016 & 0,02 & 0,005 & 0,11 & 0,621 & 1,15 & 0,616 \\
\hline & TxESF & $-7,16$ & 0,346 & 2,18 & 0,646 & 2,23 & 0,671 & $-9,08$ & 0,753 \\
\hline Estrutura & TxEst & $-0,21$ & 0,016 & $-0,09$ & 0,327 & $-0,20$ & 0,200 & $-0,57$ & 0,002 \\
\hline \multirow[t]{14}{*}{ Atendimentos } & TxAt_Diabt & 7,15 & 0,594 & 9,03 & 0,947 & $-9,83$ & 0,084 & 3,51 & 0,030 \\
\hline & TxAt_Prenatal & 36,31 & 0,079 & $-105,72$ & 0,162 & 2,10 & 0,532 & 34,23 & 0,010 \\
\hline & Pri_AB & 4899,42 & 0,000 & 8324,04 & 0,001 & 11604,12 & 0,003 & 67518,28 & 0,000 \\
\hline & TxAt_PrevCit & $-2,02$ & 0,548 & 1,18 & 0,778 & $-0,54$ & 0,562 & $-2,29$ & 0,229 \\
\hline & TxAt_HipA & 6,52 & 0,451 & 5,58 & 0,529 & 3,83 & 0,095 & 3,60 & 0,035 \\
\hline & TxNgest & 1,19 & 0,637 & 2,60 & 0,300 & $-2,37$ & 0,477 & 0,84 & 0,000 \\
\hline & TxAt_Puer & 6,42 & 0,599 & 7,98 & 0,973 & $-4,19$ & 0,187 & $-10,46$ & 0,001 \\
\hline & Tx_Consul & 14,18 & 0,013 & 1,51 & 0,396 & $-15485,03$ & 0,300 & $-69,07$ & 0,453 \\
\hline & TxEncam_Esp & $-0,19$ & 0,373 & 0,68 & 0,456 & 0,39 & 0,002 & 0,68 & 0,001 \\
\hline & TxEncam_IH & 0,05 & 0,197 & $-0,03$ & 0,031 & 0,06 & 0,535 & $-0,16$ & 0,030 \\
\hline & TxEncam_Urg & 0,38 & 0,053 & 0,08 & 0,542 & $-0,19$ & 0,447 & 0,11 & 0,170 \\
\hline & ICSAP & 0,55 & 0,879 & $-0,62$ & 0,980 & $-2,65$ & 0,361 & $-4,09$ & 0,017 \\
\hline & TxVis_med & $-83,56$ & 0,005 & 52,12 & 0,111 & $-40,62$ & 0,462 & $-46,02$ & 0,275 \\
\hline & TxPS & $-2,89$ & 0,293 & $-1,03$ & 0,323 & $-1,42$ & 0,862 & 11,15 & 0,888 \\
\hline \multirow[t]{6}{*}{ Socioeconômicas } & Txbpbf & 29,92 & 0,762 & 26,44 & 0,708 & 18,73 & 0,098 & $-9,19$ & 0,489 \\
\hline & Pip_percapita & $-5157,10$ & 0,021 & $-3786,42$ & 0,061 & $-1282,35$ & 0,693 & $-182,89$ & 0,238 \\
\hline & TxNvivos & $-5,50$ & 0,511 & $-15,70$ & 0,013 & $-17,29$ & 0,317 & $-22,82$ & 0,018 \\
\hline & Transf_capita & $-18,54$ & 0,574 & $-1,13$ & 0,031 & 25,24 & 0,141 & 49,69 & 0,007 \\
\hline & TDIS & 0,90 & 0,237 & 1,64 & 0,752 & 2,02 & 0,870 & $-1,00$ & 0,477 \\
\hline & $\mathrm{RCPC}$ & $-813,71$ & 0,168 & $-444,86$ & 0,006 & 164,39 & 0,039 & $-1018,52$ & 0,015 \\
\hline
\end{tabular}




\begin{tabular}{rrrrrrrrrr}
\hline Txagua & 5,01 & 0,005 & 2,20 & 0,284 & $-2,37$ & 0,292 & 8,24 & 0,465 \\
\hline
\end{tabular}

Obs: "Dif." consiste na diferença entre as médias dos municíp ios que aderiram ao Programa, reduzida da méd ia dos municípios que não aderiram. Logo, se a diferença for negativa, evidencia que a média nos municípios que não aderiramé superior. Já a coluna “Sig." consiste na significância do teste para cada variável.

Fonte: resultados da pesquisa.

Os resultados demonstram que nas variáveis referentes aos Recursos Humanos, os municípios do Extrato 1, que aderiram ao Programa, mantiveram a média superior de quantidade de médicos que atuam diretamente no SUS em relação à população com maior prioridade de cobertura de atenção básica (TxMed_AB). Ademais, em 2015, os municípios do Extrato 2 que aderiram ao Programa, também passaram a apresentar um valor médio superior aos municípios semelhantes que não aderiram para esta variável, apontando uma possível melhora após a adoção ao PMM. O Programa também contribuiu para melhoria da capacidade de cobertura populacional das equipes de saúde (TxESF) dos municípios do Extrato 1 que aderiram ao Programa, visto que a diferença entre os grupos deixou de ser significativa em 2015.

$\mathrm{Na}$ categoria Estrutura, os municípios que não aderiram ao PMM permaneceram com média superior nas variáveis significativas. Assim, identificou-se que o quantitativo de estabelecimentos de saúde nos municípios que não aderiram ao Programa se manteve, em média, superior ao dos municípios que aderiram nos Extratos 1 e 4 . No que se refere ao Extrato 1, a permanência da média inferior dos municípios que aderiram pode estar vinculada à dificuldade de municípios menores apresentarem atrativos para a fixação dos médicos (DUSSALT; FRANCESCHINI, 2006; PÓVOA; ANDRADE, 2006; MACIEL FILHO, 2007; SOUSA; DAL POZ; BOSCHI-PINTO, 2013; PIERANTONI, 2013; SCHEFFER; CASSENOTE; BIANCARELLI, 2015; KIRK; KIRK; MARY, 2015; OLIVEIRA et al., 2017).

Logo, a dificuldade em fixação dos médicos impossibilita a ampliação do número de estabelecimentos. Ressalta-se, contudo, que no Extrato 2, a diferença entre as médias dos grupos deixou de ser significativa, indicando uma melhora na Estrutura para os municípios que aderiram ao PMM. Inclusive, a má distribuição dos médicos associa-se à elevada rotatividade e variedade de vínculos, longas jornadas semanais, rendimentos diferenciados e plantão visto como atividade prioritária, corroborando com Lima et al. (2019).

Já na categoria Atendimentos ocorreram as maiores mudanças. No Extrato 1 os municípios que aderiram ao Programa mantiveram médias superiores no que tange à população com maior prioridade de cobertura pela atenção básica por base municipal (Pri_AB) e na proporção de encaminhamentos para atendimento de urgência e emergência (TxEncam_Urg). Ademais, os municípios que aderiram ao Programa também passaram a () $(1) \Theta$ REAd | Porto Alegre - Vol. 26 - N. ${ }^{\circ} 2$ - Maio / Agosto 2020 - p. 352-380. 
apresentar médias superiores para a taxa de atendimentos de pré-natal (TxAt_Prenatal) e na proporção de consultas médicas por habitante (Tx_Consul).

Apesar de no Extrato 1 os municípios que não ade riram ao Programa apresentarem uma média superior de visitas médicas (TxVis_med), também houve melhora no Atendimento dos municípios que aderiram. Ademais, vale ressaltar que este extrato engloba os municípios com condições mais precárias, ou seja, municípios que possuem aspectos que implicam em maiores desafios para a prestação de serviços de saúde, como fatores relativos às características do município e níveis de vulnerabilidade social (DUSSALT; FRANCESCHINI, 2006; PÓVOA; ANDRADE, 2006; MACIEL FILHO, 2007; SOUSA; DAL POZ; BOSCHI-PINTO, 2013; PIERANTONI, 2013; SCHEFFER; CASSENOTE; BIANCARELLI, 2015; KIRK; KIRK; MARY, 2015; OLIVEIRA et al., 2017).

No Extrato 2, também quanto ao Atendimento, os municípios que aderiram ao Programa mantiveram uma média superior de população com maior prioridade de cobertura pela atenção básica (Pri_AB). Contudo, a diferença entre os grupos na taxa de atendimentos por pessoa com hipertensão (TxAt_HipA), que anteriormente apresentava valor superior para os municípios que aderiram ao Programa, deixou de ser significativa. Ademais, a proporção de encaminhamento para internação hospitalar (TxEncam_IH) passou a ser superior nos municípios que não aderiram ao PMM. Contudo, tais resultados necessitam de cautela analítica, pois o fato dos municípios que não aderiram apresentarem maior proporção de encaminhamento para internação pode indicar que nos aderentes os fatores agravantes à saúde passaram a ser combatidos com antecedência, logo, reduzindo o índice de internação.

No Extrato 3, ao aderir ao PMM, os municípios melhoraram suas condições de Atendime nto, visto que das quatro variáveis que apresentaram valor médio superior no grupo dos que não ade riram em 2013, as diferenças deixaram de ser significativas no que tange à taxa de puericultura (TxAt_Puer) e proporção de Internações por Condições Sensíveis à Atenção Primária (ICS AP). Sendo assim, neste extrato, os municípios que não aderiram ao Programa permaneceram com melhores condições apenas no que tange ao atendimento de pessoas com diabetes.

Ademais, a adesão ao programa inverteu a situação de 2013 entre os grupos neste extrato, pois os municípios que aderiram passaram a apresentar uma melhor média na taxa de atendimentos por pessoa com hipertensão (TxAt_HipA), condição anterior dos que não aderiram. Logo, houve uma melhora neste atendimento, visto que tornaram os do is grupos equivalentes e inverteu a situação em um intervalo de dois anos. 
Destarte, no Extrato 3, os municípios que aderiram ao programa também apresentaram média superior e significativa de Atendimento no que tange à prioridade de cobertura pela atenção básica (Pri_AB) e proporção de encaminhamento para atendimento especializado (TxEncam_Esp).

Do mesmo modo, no Extrato 4, as médias significativas superiores de Atendimento nos municípios que não ade riram ao Programa passaram de cinco em 2013 para três em 2015. Logo, nota-se que ao aderir ao programa os municípios foram capazes de extinguir diferenças significativas no que tange à taxa de gestantes menores que 20 anos (TxNgest) e nos encaminhamentos para atendimento especializado (TxEncam_Esp).

Os municípios que não aderiram permaneceram com melhores condições de atendimento na taxa de puericultura por criança cadastrada menor de 2 anos (TxAt_Puer), proporção de encaminhamento para internação hospitalar (TxEncam_IH) e Internações por Condições Sensíveis à Atenção Primária (ICSAP). Dentre estas, destaca-se que apresentar um valor médio superior em TxEncam_IH e ICSAP, pode indicar ausência de atendimentos que evitam problemas agravantes de saúde.

Ademais, os municípios que aderiram ao programa apresentaram, em 2015, melhores condições de atendimento na média de atendimentos por pessoa com diabetes (TxAt_Diabt), na taxa de atendimento pré-natal (TxAt_Prenatal), na população com maior prioridade de cobertura pela atenção básica (Pri_AB), na taxa de atendimentos por pessoa com hipertensão (TxAt_HipA), no número de gestantes menores de 20 anos cadastradas (TxNgest), na proporção de encaminhamento para atendimento especializado (TxEncam_Esp) e atendimento de urgência e emergência (TxEncam_Urg). Tais resultados apontam melhora significativa nas condições de atendimento dos municípios que aderiram ao PMM pertencentes ao Extrato 4.

Logo, dentre todos os extratos, foi no Extrato 4 que houve melhora no maior número de critérios de Atendimento. Este resultado se justifica por ser o extrato com melhores condições sociais e maior faixa populacional, fatores que afetam positivamente a qualidade dos serviços prestados, em virtude das condições de infraestrutura favoráveis (CAMPOS; MALIK, 2008; GIOVANELLA et al., 2016).

Por fim, no que tange às Condições Socioeconômicas, no Extrato 3 os municípios que aderiram apresentaram valor médio superior para todas as variáveis da categoria. Já no que tange ao Produto Interno Bruto per capita (Pip_percapita) e à frequência de nascidos vivos de baixo peso (TxNvivos), os municípios que não aderiram apresentaram melhores resultados. 
Já as demais variáveis, quando significativas, não apresentaram padrão de comportamento, sendo superior às vezes para os municípios que aderiram e, em outros casos, aos que não aderiram. Contudo, é mais frequente a média ser superior aos municípios que não aderiram, indicando que os municípios que aderiram ao PMM, de fato, possuem condições socioeconômicas inferiores a seus pares, justific ando a aderência ao programa.

\section{CONSIDERAÇÕES FINAIS}

Observa-se, portanto, que o Programa Mais Médicos trouxe diversos avanços para o desempenho da Atenção Primária à Saúde como aumento do número de médicos nesta modalidade de atendimento; expansão das equipes da Estratégia Saúde da Família; ampliação da cobertura da APS com maior agilidade ; aumento do número de consultas; expansão do número de procedimentos de $\mathrm{AB}$ e redução das internações sensíveis à APS.

Ademais, verificou-se que municípios em vulnerabilidade muitas vezes não possuem infraestrutura e recursos financeiros para receber esses profissionais, ou seja, o município recebe a política do governo federal, mas não possui as condições adequadas para retornar e cumprir suas metas de forma eficaz.

Contudo, apesar dos municípios que aderiram ao PMM ainda possuírem condições socioeconômicas inferiores a seus pares, justificando a sua aderência, houve uma melhora em diversos indicadores da atenção básica. Demonstrando, assim, a importância dessa política pública para diminuição das iniquidades de saúde no Brasil, principalmente no que se referem aos recursos humanos médicos e à atenção básica.

O presente artigo se destaca dos demais por trazer uma comparação dos anos 2013 e 2015, especialmente, na equalização das diferenças entre municípios sem estrutura de serviços (extrato 1) e os mais estruturados (extrato 4). Para trabalhos futuros, recomenda-se ampliar a análise para outros Estados brasileiros e analisar resultados dos outros dois eixos do programa: "melhoria de infraestrutura das Unidades Básicas de Saúde" e "ampliação e capacitação profissional dos médicos no Brasil”. Além disso, incluir variáveis sobre gastos de saúde no município para analisar o quanto os fatores financeiros afetam no seu desempenho.

\section{REFERÊNCIAS}


ALMEIDA, P. F.; FAUSTO, M. C. R.; GIOVANELLA, L. Fortalecimento da atenção primária à saúde: estratégia para potencializar a coordenação dos cuidados. Revista Panamericana de Salud Pública, v. 29, p. 84-95, 2011.

ARAUJO, G. C. de. A relação entre federalismo e municipalização: desafios para a construção do sistema nacional e articulado de educação no Brasil. Educação e Pesquisa, v. 36, n. 1, p. 389-402, 2010.

BRASIL. Constituição de 1988. Constituição da República Federativa do Brasil. Brasília, DF: Senado Federal, 1988.

BRASIL. MINISTÉRIO DA S AÚDE. Manual de atuação na atenção básica à saúde, 2011. Disponível

<http://www.mpse.mp.br/CoordenadoriaGeral/AbrirDocumento.aspx?cd_docume nto=182>.

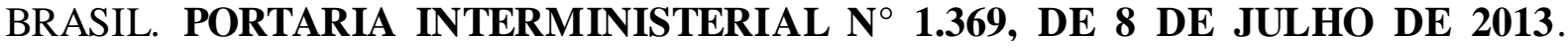
Dispõe sobre a implementação do Programa Mais Médicos para o Brasil. Diário Oficial da União 2013; 9 jun. 2013.

BRASIL. Programa mais médicos - dois anos: mais saúde para os brasileiros. Brasília: Ministério da Saúde, Secretaria de Gestão do Trabalho e da Educação na Saúde, 2015.

BRUNI, A. L. Estatística Aplicada a Gestão Empresarial. $2^{a}$ Ed., São Paulo, Editora Atlas, 2010 .

CAMPOS C. V. A.; MALIK A. M. Satisfação no trabalho e rotatividade dos médicos do Programa Saúde da Família. Revista de Administração Pública, v. 42, n. 2, p. 347-368, 2008.

CARNEIRO et al. EST - 220: Estatística experime ntal. Viçosa, 2010.

COMES, Yamila et al. Avaliação da satisfação dos usuários e da responsividade dos serviços em municípios inscritos no Programa Mais Médicos. Ciência \& Saúde Coletiva, v. 21, p. 2749-2759, 2016.

DEMOGRAFIA MÉDICA NO BRASIL 2018 / Coordenação de Mário Scheffer; equipe de pesquisa: Alex Cassenote, Aline Gil Alves Guilloux, Aureliano Biancarelli, Bruno Alonso Miotto e Giulia Marcelino Mainardi. São Paulo: Conselho Regional de Medicina do Estado de São Paulo: Conselho Federal de Medicina, 2018.

DUSSAULT, G.; FRANCESCHINI, M. C. Not enough there, too many here: understanding geographical imbalances in the distribution of the health workforce. Human resources for health, v. 4, n. 1, p. 12, 2006.

FEDERAÇÃO NACIONAL DOS MÉDICOS-FENAM. Protestos pelo país contra a importação de médicos estrangeiros sem o Revalida. 29 maio 2013. Disponível em: <http://portal.fenam2.org.br/portal/showData/404292\#.>. Acesso em: 15 jun. 2018.

GIOVANELlA, L. et al. A provisão emergencial de médicos pelo Programa Mais Médicos e a qualidade da estrutura das unidades básicas de saúde. Ciência \& Saúde Coletiva, v. 21, p. 2697-2708, 2016.

GIRARDI S. N.; CARVALHO C. L.; ARAÚJO J. F.; FARAH J. M.; WAN DER MAAS L.; CAMPOS L. A. Índice de escassez de médicos no Brasil: estudo exploratório no âmbito da Atenção Primária. In: Pierantoni CR, Dal Poz MR, França T, organizadores. O trabalho em Saúde: abordagens quantitativas e qualitativas. Rio de Janeiro: Cepesc/IMS/UERJ, ObservaRH, p. 171-186, 2011. 
KIRK J. M.; KIRK E.J.; MARY S. Mais Médicos: Cuba's Medical Internationalism Programme in Brazil. Bulletin of Latin American Research, v. 35, n. 4, p. 467-480, 2016.

LEVIN, J.; FOX, J. A.; FORDE, D. R. Estatística para Ciências Humanas. 11ª Ed., São Paulo, Pearson, 2010.

LIMA, L. D.; CARVAlho, M. S.; COELI, C. M. Médicos, Políticas e Sistemas de Saúde. Cadernos de Saúde Pública. v. 35,n. 1, p. 1-4, 2019.

MACHADO, F. A. S. M. et al. Integralidade, formação de saúde, educação em saúde e as propostas do SUS - uma revisão conceitual. Ciência \& Saúde Coletiva, v. 12, n. 2, p.335342, 2007.

MACIEL FILHO, R. Estratégias para a distribuição e fixação e médicos em sistemas nacionais de saúde : o caso brasileiro. Rio de Janeiro: UERJ, 2007.

MARTIN, D. G.; FERREIRA, M. A. M.; FARIA, E. R. de; SILVA, F. C. da. Caminhos para a Promoção do Desempenho da Saúde Pública e o Papel do Controle Social. In: EnAnpad, 2018, Curitiba. Anais...Curitiba: Anpad, 2018. Administração Pública.

MELO, M. F. S.; FERNANDES, S. B. S.; OLIVEIRA, Francisca de Fátima Araújo. Federalismo, descentralização e municipalização: desafios das políticas públicas para a gestão educacional. HOLOS, v. 3, p. 51-61, 2017.

MENDONÇA, C. S.; DIERCKS, M. S.; KOPITTKE, L.. O fortalecimento da Atenção Primária à Saúde nos municípios da Região Metropolitana de Porto Alegre, Brasil, após a inserção no Programa Mais Médicos: uma comparação intermunicipal. Ciência \& Saúde Coletiva, v. 21, p. 2871-2878, 2016.

MOREIRA, K. S.; LIMA, C. A.; VIEIRA, M. A.; COSTA, S. M. Avaliação da infraestrutura das unidades de saúde da família e equipame ntos para ações na atenção básica. Cogitare Enfermagem, v. 22, n. 2, 2017.

NETO, L. M. F.; LIMA, P. L. S.. Acesso à Saúde no Brasil: O Programa Mais Médicos e os problemas para efetivação da garantia constitucional. Percurso, v. 3, n. 30, p. 57-79, 2019.

OLIVEIRA, A. P. C. de et al. Desafios para assegurar a disponibilidade e acessibilidade à assistência médica no Sistema Único de Saúde. Ciência e Saúde Coletiva, Rio de Janeiro, v. 22, n. 4, p. 1165-1180, 2017.

OLIVEIRA, J.P. A.; SANCHEZ, M. N.; SANTOS, L. M. P.. O Programa Mais Médicos: provimento de médicos em municípios brasileiros prioritários entre 2013 e 2014. Ciência \& Saúde Coletiva, v. 21, p. 2719-2727, 2016.

PIERANTONI, C. R.; MIRANDA, R.; MAGNAGO, C. Fortalecimento da Capacidade de Plane jamento de Recursos Humanos para Sistemas Nacionais de Saúde. Belo Horizonte: UFMG, 2013.

PÓVOA, L.; ANDRADE, M. V. Geographic distribution of physicians in Brazil: an analysis based on a locational choice model. Cadernos de Saúde Pública, v. 22, n. 8, p. 15551564, 2006.

SANTOS, B. Federalismo e Desenvolvimento urbano. Cadernos UniFOA, v. 1, n. 1, p. 5570, 2017.

SCHEFFER, M.; CASSENOTE, A. B. A. Demografia Médica no Brasil. São Paulo: FMUSP; 2015. 
SOUSA, A.; DAL POZ, M. R.; BOSCHI-PINTO, C. Reducing inequities in neonatal mortality through adequate supply of health workers: evidence from newborn health in Brazil. PLoS One, v. 8, n. 9, p. e74772, 2013.

STARFIELD, B. Atenção Primária: equilíbrio entre necessidades de saúde, serviços e tec nologia. Brasília: UNESCO/Ministério da Saúde; 20. 